\title{
EXPLORING THE USE OF GAME MAKING ACROSS THE SCHOOL CURRICULUM
}

\author{
H. Boulton ${ }^{1}$, T. Hughes-Roberts ${ }^{1}$, D. Brown ${ }^{1}$, X. Beltran ${ }^{2}$, J. Tinney ${ }^{1}$,

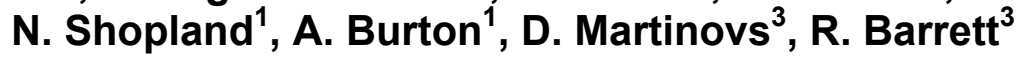 \\ ${ }^{1}$ Nottingham Trent University (UNITED KINGDOM) \\ ${ }^{2}$ Inmark (SPAIN) \\ ${ }^{3}$ National Video Arcade (UNITED KINGDOM)
}

\begin{abstract}
Computer games as part of education is a well-established topic for research, suggesting that creating games is linked to a range of cognitive and behavioural outcomes. Creating games in all subject disciplines is becoming increasingly possible due to the increasingly higher status of computing in schools across Europe and the prevalence of visual programming languages such as Scratch and Pocket Code. The use of games within education is not new; in a systematic review of 129 papers [1] found that playing games impacts across a range of areas including engagement, cognitive ability and, most commonly, knowledge acquisition and content understanding. However, while research has thus far examined game play and game based learning in education there is limited work focussing on the process of game creation as a method of classroom teaching. This is a prospect which is increasingly possible with the introduction of visual programming languages such as Scratch [2] and Pocket Code. It is suggested that playful learning through computer games could stimulate students' intrinsic motivation ([3] and that knowledge creation can emerge through the construction of artefacts in a playful learning environment via the co-creation of games [4].

The research presented in this paper is from a pilot study examining the impact of game making in traditional primary and secondary school classrooms (5-18 years) in the United Kingdom (UK). The research, funded by Horizon 2020, is part of a wider European project; No-one Left Behind. In the UK the project has introduced game making into disciplines such as Religious Education, Science and History. Data indicates that although not all students found this a positive experience, computational thinking skills have increased, and students, disaffected with their learning, have re-engaged with learning, increasing their persistence and resulting in a deeper understanding of subject knowledge. In addition initial results suggest that game making has the potential to increase engagement with classroom learning and lead to increased learner satisfaction within lessons. Non-computing teachers have gained in confidence in developing game creation in their subject discipline, increasing their awareness of computational thinking. Barriers identified include teacher familiarity with programming as a means to teach non-STEM subject knowledge, a potential to decrease knowledge acquisition during the process of familiarisation with the teaching tool and a need for software developers to consider design for children with SEND. The project is changing the learning environment and emerging pedagogy has been identified which will be shared in this paper. As a result of the study lesson resources have been created for teachers to use across disciplines which are now available via the project URL; these will be shared in this paper.
\end{abstract}

Keywords: Innovation, technology, research projects, game making, inclusive education, assistive technology, primary education, secondary education.

\section{INTRODUCTION}

Computer games as part of education is a well-established topic for research, suggesting that creating games is linked to a range of cognitive and behavioural outcomes. Creating games in all subject disciplines is becoming increasingly possible due to the increasingly higher status of computing in schools across Europe and the prevalence of visual programming languages such as Scratch and Pocket Code.

As visual programming games, such as Scratch [2] and Pocket Code, have become freely available for use in primary and secondary classrooms there is increased opportunity to develop gaming across disciplines. Research has focused on game playing and game based learning in the classroom; this paper focusses on the process of game creation as a method of classroom teaching. This paper 
therefore contributes new understandings of how creating games across disciplines in primary and secondary schools can improve engagement and learning.

The research presented in this paper reports findings from a pilot study examining the impact of game making across disciplines in primary and secondary school classrooms (5-18 years) in the United Kingdom (UK). The research, funded by Horizon 2020, is part of a wider European project. In the UK the project has introduced game making into disciplines such as Religious Education, Science and History with a specific focus on using gaming with learners at risk of exclusion, such as those with special educational needs, disability or learning in their second language.

Contemporary literature suggests that playing games can improve engagement, cognitive ability, knowledge acquisition and content understanding [1]. Garris, Ahlers, \& Driskell [3] identified that learning through using computer games could impact on learners' intrinsic motivation. Kangas [4] suggested that knowledge creation could emerge through co-creating games and artefacts in a playful learning environment. Fessakis et al. [5] and Kalelioglu \& [6] identified a significant increase in problem-solving for learners using gaming as a tool for learning.

The literature also recognised barriers to using new technologies in classrooms. For example, access to technology [7] [8] teacher confidence [9] resistance to change and lack of time to learn new technologies [10].

This paper presents the pilot study which spanned an academic year in 3 disciplines across 3 schools, including the preparation for the study, procuring appropriate technologies, training teachers, managing the technologies within school, the intervention, data collection and analysis and the creation of teaching materials to be shared. The gaming programme used for the project is Pocket Code, Pocket Code, a visual, "LEGO-style" (see Figure 1) programming environment which allows you to create, play, share, and remix. The software is free to download from Catrobat.org, and allows users to develop games, animations, interactive music videos, directly onto the user's phone or tablet. The output of this study is a game-making framework and classroom resources.

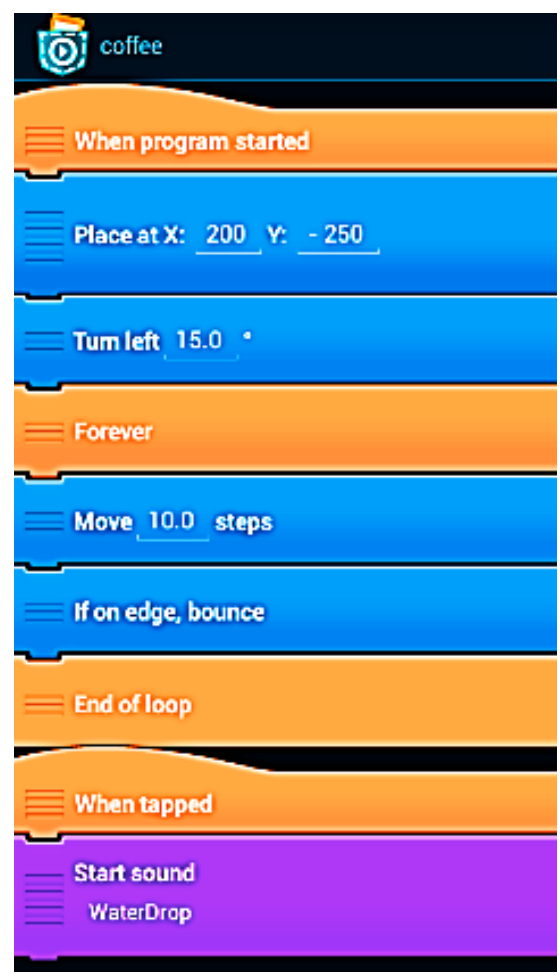

Figure 1: Example of Pocket Code.

\section{METHODOLOGY}

Three schools were invited to take part in the study, each of which was involved in the wider Horizon 2020 project. One group in each school was selected to take part to reflect the use of game making in four different disciplines: science, religious education, employability and history. The core criteria was 
groups with learners who were at risk of social exclusion. Due to the nature of the learners involved teaching assistants (TA) were also included in the study. The groups and the teachers involved are set out in Table 1.

Table 1: Overview of schools taking part in the study.

\begin{tabular}{|c|c|c|c|c|}
\hline School & Level (N) & Subject & Schools & Teachers \\
\hline $\begin{array}{c}A=\text { special } \\
\text { school }\end{array}$ & $\begin{array}{l}\text { Year } 9-14 \\
(N=12) \\
\text { Ages 13-18 }\end{array}$ & $\begin{array}{l}\text { Cross curricular: } \\
\text { employability. }\end{array}$ & $\begin{array}{c}\text { Diverse range of } \\
\text { students with SEND } \\
\text { in a specialist school. }\end{array}$ & $\begin{array}{c}1 \text { teacher and } 1 \\
\text { teaching assistant (TA) } \\
\text { working at Entry level. }\end{array}$ \\
\hline $\begin{array}{c}B= \\
\text { mainstream } \\
\text { secondary } \\
\text { school }\end{array}$ & $\begin{array}{c}\text { Year } 8 \\
(N=15) \\
\text { Ages 12-13 } \\
\text { Year } 9 \\
(N=15) \\
\text { Ages 13-14 }\end{array}$ & $\begin{array}{l}\text { Science and } \\
\text { religious } \\
\text { education. }\end{array}$ & $\begin{array}{l}\text { SEND learners in } \\
\text { mainstream school. }\end{array}$ & $\begin{array}{c}3 \text { teachers: } 2 \text { working at } \\
\text { Entry level; } 1 \text { working at } \\
\text { Core level. }\end{array}$ \\
\hline $\begin{array}{c}\mathrm{C}= \\
\text { mainstream } \\
\text { primary } \\
\text { school }\end{array}$ & $\begin{array}{c}\text { Year } 5 \\
(\mathrm{~N}=15) \\
\text { Ages } 10-11\end{array}$ & History. & $\begin{array}{l}\text { SEND learners in } \\
\text { mainstream school. }\end{array}$ & $\begin{array}{l}1 \text { teacher working at } \\
\text { developer level. }\end{array}$ \\
\hline
\end{tabular}

Once the schools and groups had been identified tablets were purchased; 7" tablets were purchased for mainstream schools, 10" were purchased for learners at the special school who had profound and multiple learning disorders including restricted movement and sight. The next stage involved downloading Pocket Code onto the tablets, setting up individual log on and passwords, ensuring the tablets would connect to each school's wifi and training the teachers. In order to plan appropriate training for teachers a questionnaire, developed by Leicester City Council (2013) was adapted to measure individual teacher's digital literacy and game playing experience. This questionnaire identifies different levels of teachers: entry, core, developer and pioneer. The initial training session for teachers, differentiated to meet the needs of each teacher having identified their level, was held at each school, lasting 2 hours. The TPACK framework developed by Harris, Mishra \& Koehler (2009) provided the basis for the training, that is, building confidence with the teachers in using the technology $(T)$, sharing appropriate pedagogy $(P)$ within the content knowledge (CK) for each discipline.

As this was the pilot phase lessons were led by a researcher working on the project who had also trained as a teacher. The role of the teacher was to provide support during lessons. During the year long study, all teachers were brought together to discuss their experiences, what was working well and challenges every 6 weeks. Materials to support the use of game-making across disciplines were developed and trialled during the project. Teachers were interviewed prior to the start of the project going into their classrooms and at the conclusion of the intervention.

The learners also completed a short questionnaire to identify their prior experience of game playing and game making. Of the learners taking part each group had a mix of those who were experienced game players and less experienced game players. Only one group in School B had 2 students who had created their own games. In addition each learner's computational thinking ability was measured using an open source test; this was applied prior to the intervention as a baseline measure and at completion of the intervention to identify any changes. As none of the learners had prior experience of Pocket Code, an introductory, one hour session was implemented.

As the study developed a new framework was created which included the leisure game environment, Pocket Code and the pedagogical knowledge and content as shown in Figure 2. 


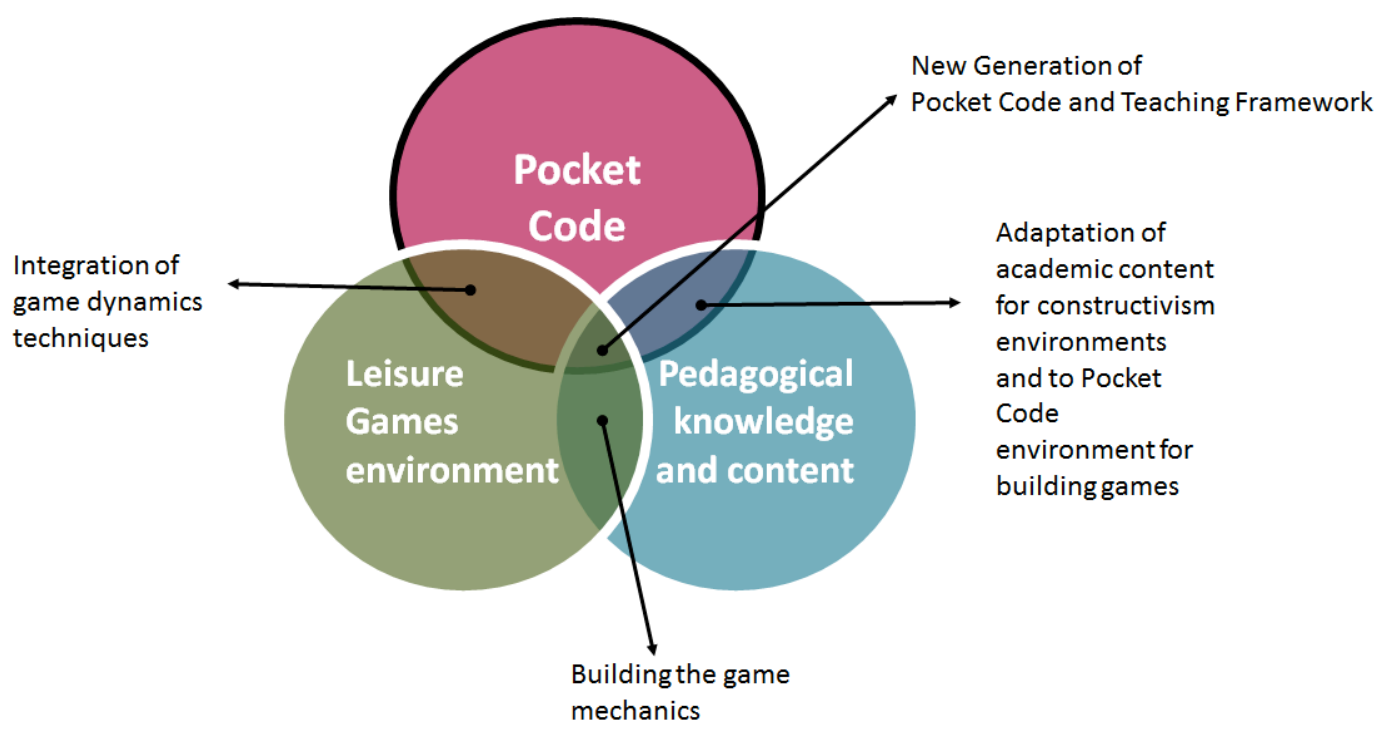

Figure 2: Pocket Code Framework.

Once the teachers were trained the intervention took place. The intervention at each school followed the same process, that is an intervention lasting 12 weeks, with one lesson for each discipline each week.

\section{RESULTS}

Data indicates that students, disaffected with their learning, have re-engaged with learning, increasing their persistence and impacting on increased intrinsic motivation. Improved behaviour has consistently been commented on by all teachers involved in the project. Comments include:

'There is a high level of behavioural problems in the class, however we have not needed to withdraw any children from lessons where project lessons are taking place. This is evidenced through our school-wide behavior system.' (Teacher C2).

School C found behavior was a particular problem in the afternoon. However this was not the case where project lessons were held in the afternoon:

'Afternoons can be difficult in terms of behavior. When using the tablets the pupils' behavior is much improved'. I think when you look at some of the children, 2 of the lads, especially in the afternoon they have settled much better in those lessons because they are completely engaged in the class. They don't want to risk not being in that class.' (Teacher C1).

'The students are calmer and less teacher assistance is needed on the project lessons'. (Teacher A1)

Focus group interviews with teachers suggests the intervention has resulted in a deeper understanding of subject knowledge. In addition initial results suggest that game making has the potential to increase engagement with classroom learning and lead to increased learner satisfaction within lessons. For example one teacher, who was the deputy head teacher at school C commented that during the lessons where game making was experienced there were less behavioural problems and learners remained on task much longer. This was supported at interview by teachers in school B and evidenced from the teachers' records using Class DoJo. Further data to support this will be collated in the next phase of the project.

The teachers, who were discipline teachers, rather than computing teachers, who had limited knowledge of programming, have gained in confidence in developing game creation in their subject discipline, increasing their awareness of computational thinking. Teachers commented that students were improving their computational thinking skills; in the next phase data will be collected at the beginning and end using computational thinking tests. In this phase the tests were trialled. In school $C$ the results were of surprise to the teachers:

'It is quite easy to group our children within their class, however, in the tests [name of student] had a fantastic score. In any other test she panics but in this one she got on and did it'. (Teacher C1). 
Barriers to the implementation of game creating identified include teacher familiarity with programming as a means to teach non-STEM subject knowledge, a potential to decrease knowledge acquisition during the process of familiarisation with the teaching tool and a need for software developers to consider design for children with special educational needs and disabilities.

As the pilot progressed the project identified that the students, who all had learning difficulties, were finding the programming element challenging, but enjoyed creating the games. It was therefore agreed part-way through the pilot to trial using pre-set games. The teachers commented that this change was leading to a deeper level of learning the subject:

'The new focus on pre-set games went well with the level of the student's ability in the science group. There was renewed excitement for the project'. (Teacher B2).

'They are loving playing the games and increasing their scores. The change in focus means we can move onto sequencing, which they found difficult before.' (Teacher A1).

The project is changing the learning environment and emerging pedagogy has been identified. A module framework for delivery of Pocket Code, which can be applied to game making has been developed as shown in Figure 3.

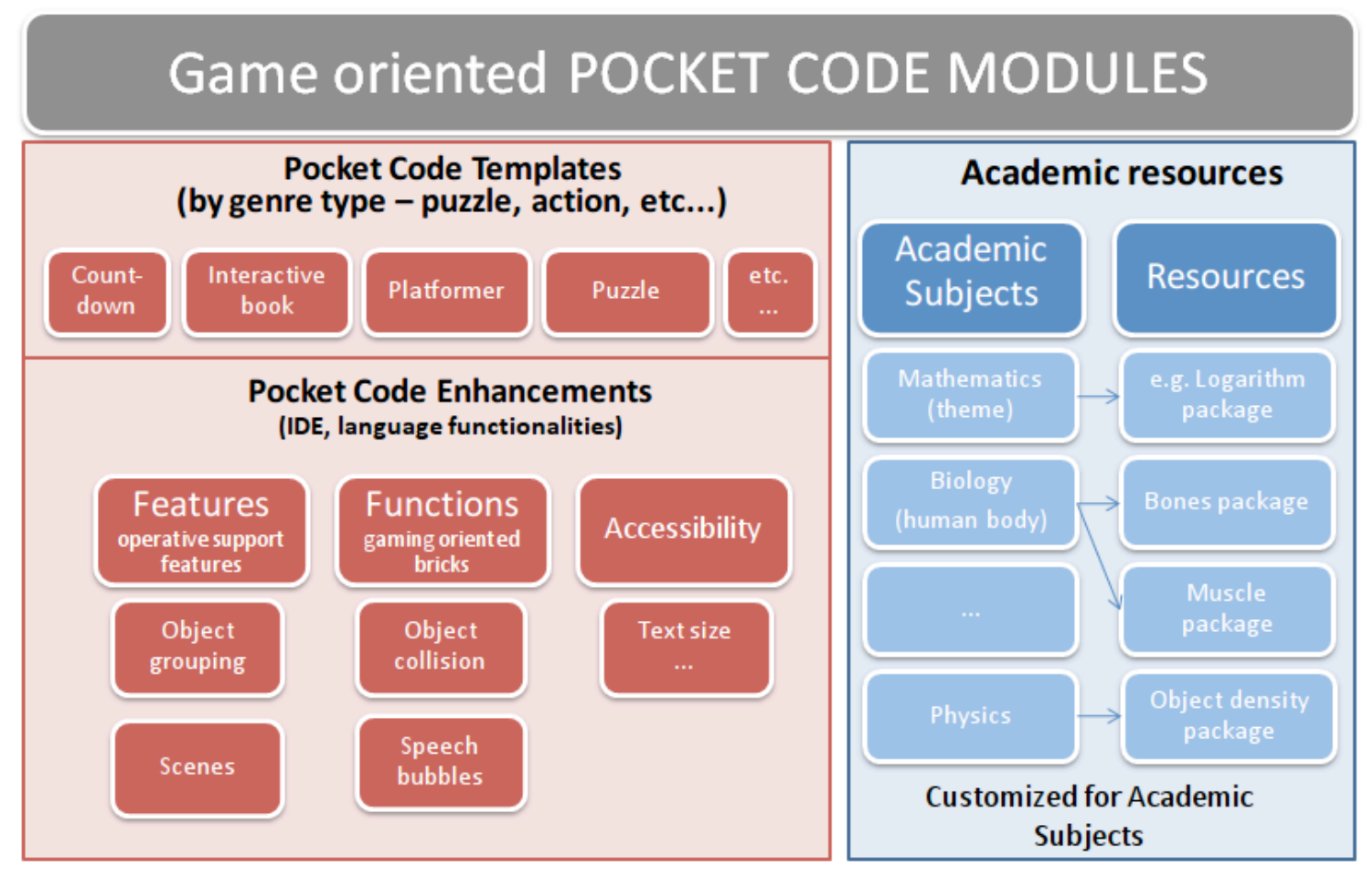

Figure 3: Framework for modules.

In addition to the Module framework the study has supported the development of a gaming template for Pocket Code:

- A Title Screen: A graphically pleasing introduction/loading screen.

- An Instructions Screen: This will convey both "goal" and "rules".

- One or More Levels: Use of the word "level" creates an intuitive connection with the world of commercial games, a great majority of which still use the concept of a "level" in one form or another.

- A Game Over Screen: "Game Over" might be linked to success, or failure; the end of a story; the expiration of a time limit, the achievement of a target, the outcome of a competition, or any combination of those elements.

- A Pause Screen: Pause screens give players the opportunity to suspend gameplay, this element will become more relevant as the pupils and modules advance in their use of Pocket Code. 
As a result of the study lesson resources have been created for teachers to use across disciplines which are now available via the project URL, which includes a lesson plan template that can be used across all subject disciplines. The lesson plan template was developed following interviews with teachers; this has evolved during the intervention to take account of different disciplines and types of learners. The project identified the importance of developing a template that was sufficiently flexible to meet the needs of the school ethos and pedagogy of the discipline. For example, at school $A$, the intervention was found to be most successful in engaging the learners and motivating them to learn, was through creating their own assets, rather than learning to programme, thus focusing on subject content. The final lesson plan includes opportunity to have learning outcomes for both the subject discipline and game creation, provides space for the subject knowledge, and helps the teacher consider the process of assessment and feedback. Within the lesson plan is a section for teachers to show the process of the lesson in three key stages: content to start with reflecting back to previous learning and introducing new learning for the lesson, content for the main learning, including extension work for more able learners, and a plenary section for reflection on learning, assessment of learning and feedback on progression as well as target setting for the next lesson.

Overall it was identified that learners were more engaged where they could create their own artefacts rather than using pre-prepared artefacts. For example, in the employability module at the special school, students were encouraged to take photographs, using the tablets, of what they needed to wear, their route to work, the jobs they would be doing etc. In the science lessons the learners were encouraged to take images, using the tablets of their preparation for experiments, and the experiment in progress. In the history lessons at the primary school where they were learning about Victorian England the learners were encouraged to find images of their own for homework, bring these into the lesson, then take images which they could incorporate into their games. Learners were also encouraged to create their own sounds and either create, or use, their own music and sounds within the game. Observation data indicates that engagement levels are higher when learners take ownership of their individual images and sounds within their games.

Data from interviews with the teachers indicated their growing confidence in using Pocket Code and in supporting the learners in the classroom. In the initial interviews all teachers expressed concern at their lack of programming experience, however they quickly found the construction of the bricks and the order of the games provided a framework. The teachers, used to being the expert in the classroom with their subject knowledge had to make the transition to being a student as some learners overtook their knowledge. Careful management of the classrooms and developing pedagogy resulted in a reversal of role as teachers learnt from those learners who progressed more quickly.

It became evident from the study that teachers needed a data collection tool which measures the progress of individual learners in terms of game creation, time of connection and time spent creating the games. They identified the following as important:

- Period of time on task;

- Measuring persistence: how many times do learners repeat to complete;

- Measuring learner's programming skill;

- Collaboration: identifying individual learner's contribution when creating games in groups;

- What types of games are the most popular?

- Measuring out of school learning and engagement.

These have all been fed into the design of Pocket Code; a teachers' control panel is under development and will be included in the next phase of its development.

A further finding was that the learners with significant learning difficulties and those learning in their second language, struggled with the text on the bricks and some of the language on the bricks:

'One of the students was working at looking at the coloured bricks and trying to make the game look the same as the example. I think they were using the shapes and colours of the blocks as he can't read.' (Teacher A1)

This has been fed back to the designers who will provide meaningful symbols on the bricks for the next release of the software. This development should ensure that children with a range of learning difficulties will be able to create games and engage with game jams.

In order to integrate the Game-making framework into practical processes and steps for teachers to guide the implementation of game-based learning into their classrooms, the study has facilitated the 
design of a three step guide involving planning, teaching and improving. This has been adapted from the "plan, do, check, act" methodology (also known as Deming Circle) ${ }^{1}$. We selected this methodology to enable a continuous improvement of processes in teaching. Figure 4 illustrates the methodology which reflects game-making pedagogy across all disciplines in primary and seconddary classrooms, that is planning for teaching, the teaching and learning process and the process of assessment of learning.

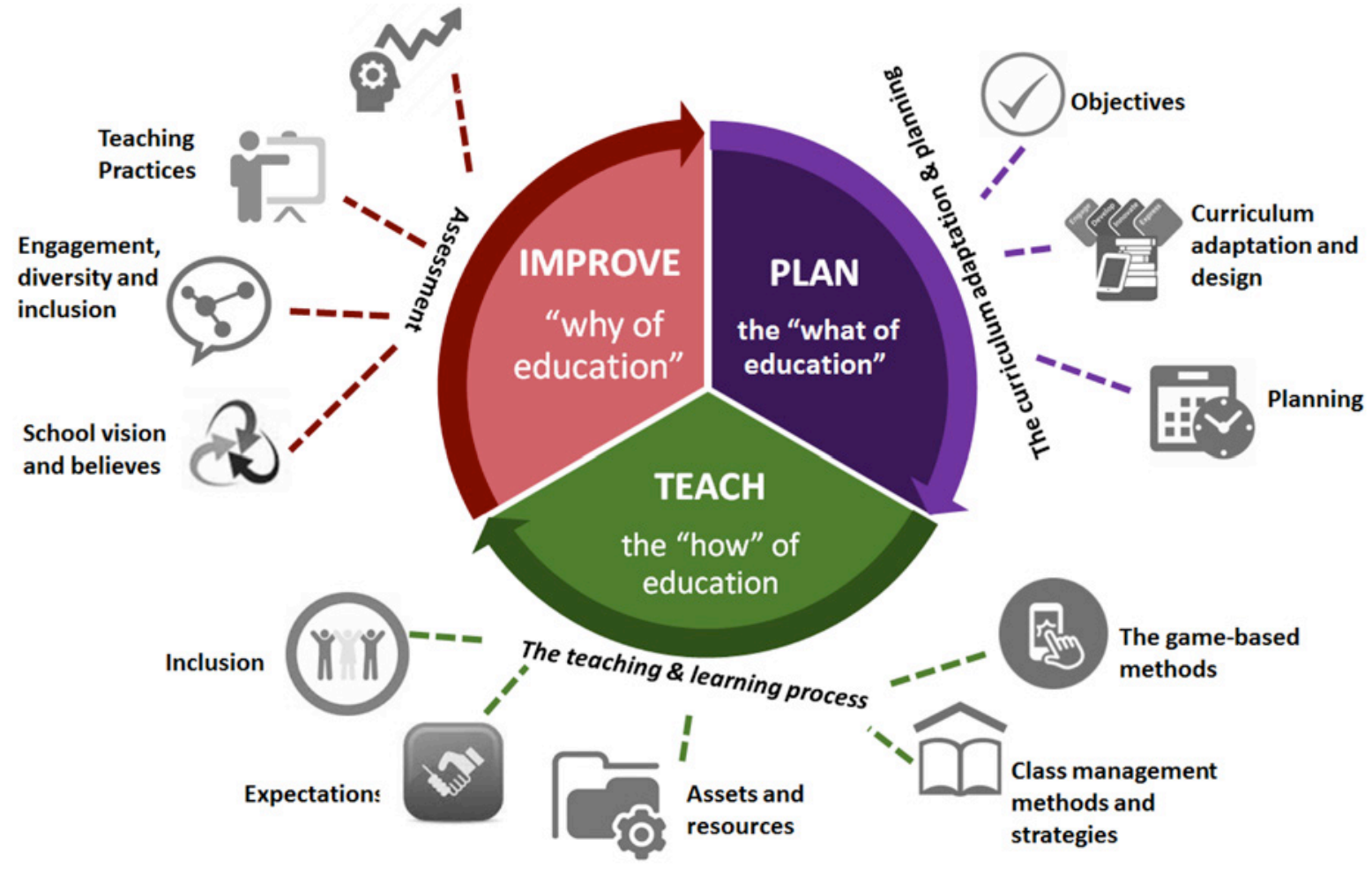

Figure 4: 3-stage pedagogic model.

\section{CONCLUSIONS}

The teaching framework that has been developed from this study, which is based on evidence, indicates that teachers across disciplines, with little understanding of programming, have the potential to introduce game creating into their classrooms as an exciting and engaging learning resource. Initial training in Pocket Code was needed and training resources have been created, which are free to all teachers, to download. In addition a module framework has been designed which can be adapted by teachers wanting to use game making in their classrooms. The study identified that learners are engaged when using game making in learning, particularly when they are able to create their own artefacts. We have also identified that learners with severe learning difficulties and those learning in their second language need a slightly different system with symbols rather than text on the bricks. There is a need to support teachers in the development of pedagogy; lesson plan structures and the 3 stage pedagogic model provide initial resources. However, with careful planning, ensuring teachers are trained and supported with appropriate resources and time to introduce game making into lessons, together with appropriate structures and pedagogy, this study contributes to growing evidence that game making can result in higher levels of engagement, the development of computational thinking, knowledge creation and a greater level of discipline knowledge, while also impacting on intrinsic motivation of learners. Further resources are available on the project web site.

\footnotetext{
${ }^{1}$ Deming Circle is an iterative management method used in business for continuous improvement of processes; it is based in four phases: plan, do, check, act (https://www.deming.org/theman/theories/pdsacycle)
} 


\section{ACKNOWLEDGEMENTS}

We acknowledge the funders of this Horizon 2020 project, Grant Agreement 645215. We also acknowledge the contributions from the full project team in completing the study, and in producing this paper: INMARK Estudios y Estrategias, Spain; Universidad Politecnica De Madrid, Spain; Game City, United Kingdom; PYRO studios/Grupo SED, Spain; Graz University of Technology, Austria, Honchshule der Medien, Germany.

\section{REFERENCES}

[1] T. Connolly, E. Boyle, E. MacArthur, T. Hainey, \& J. Boyle. A systematic literature review of empirical evidence on computer games and serious games. Computers \& Education, 59 (2), 661-686, 2012

[2] M. Resnick, J. Maloney, A. Monroy-Hernandez, N. Rusk, E. Eastmond, K. Brennan, A. Millner, E. Rosenbaum, J. Silver, \& B. Silverman. Scratch: programming for all. Communications of the ACM, 52 (11), 60-67, 2009.

[3] R. Garris, R. Ahlers, \& J. Driskell. Games, motivation, and learning: A research and practice model. Simulation \& Gaming, 33 (4), 441-467, 2002.

[4] M. Kangas, Creative and playful learning: Learning through game co-creation and games in a playful learning environment. Thinking Skills and Creativity, 5 (1), 1-15, 2010.

[5] G. Fessakis, E. Gouli, \& E. Mavroudi. Problem solving by 5-6 years old kindergarten children in a computer programming environment: A case study. Computers \& Education, 63, 87-97, 2013.

[6] Y. Gulbahar \& F. Kalelioglu. The effects of teaching programming via Scratch on problem solving skills: A discussion from learners' perspective. Informatics in Education-an International Journal, (Vol13_1), 33-50, 2014.

[7] H. Boulton, \& A. Hramiak. Cascading the use of Web 2.0 technology in secondary schools in the United Kingdom: identifying the barriers beyond pre-service training. Technology, Pedagogy and Education, 23 (2), 151-165 2014.

[8] W. J. Pelgrum, \& B.G. Doornekamp. Indicators on ICT in primary and secondary education. Retrieved from http://ec.europa.eu/education/more-information/doc/ictindicrep_en.pdf, 2009 [accessed 20 Dec 2016].

[9] S. Murray, J. Nuttall, \& J. Mitchell. Research into initial teacher education in Australia: A survey of the literature 1995-2004. Teaching and Teacher Education, 24 (1), 225-239, 2008.

[10] K. A. Bingimlas. Barriers to the successful integration of ICT in teaching and learning environments: A review of the literature. Eurasia Journal of Mathematics, Science \& Technology Education, 5 (3), 235-245, 2009. 